University of Nebraska - Lincoln

DigitalCommons@University of Nebraska - Lincoln

Faculty Papers and Publications in Animal

Science

Animal Science Department

2006

\title{
Sorting Strategies for Long Yearling Cattle Grown in an Extensive Forage Utilization Beef Production System
}

James C. Macdonald

University of Nebraska-Lincoln, jmacdonald2@unl.edu

T. J. Klopfenstein

University of Nebraska-Lincoln, tklopfenstein1@unl.edu

G. E. Erickson

University of Nebraska-Lincoln, gerickson4@unl.edu

C. N. Macken

University of Nebraska-Lincoln

J. D. Folmer

University of Nebraska-Lincoln

See next page for additional authors

Follow this and additional works at: https://digitalcommons.unl.edu/animalscifacpub

Part of the Animal Sciences Commons

Macdonald, James C.; Klopfenstein, T. J.; Erickson, G. E.; Macken, C. N.; Folmer, J. D.; and Blackford, M. P., "Sorting Strategies for Long Yearling Cattle Grown in an Extensive Forage Utilization Beef Production System" (2006). Faculty Papers and Publications in Animal Science. 769.

https://digitalcommons.unl.edu/animalscifacpub/769

This Article is brought to you for free and open access by the Animal Science Department at DigitalCommons@University of Nebraska - Lincoln. It has been accepted for inclusion in Faculty Papers and Publications in Animal Science by an authorized administrator of DigitalCommons@University of Nebraska - Lincoln. 


\section{Authors}

James C. Macdonald, T. J. Klopfenstein, G. E. Erickson, C. N. Macken, J. D. Folmer, and M. P. Blackford 


\section{$\pi$ \\ Sorting Strategies for Long Yearling Cattle Grown in an Extensive Forage Utilization Beef Production System ${ }^{1}$}

J. C. MACDONALD, PAS, T. J. KLOPFENSTEIN, ${ }^{2}$ G. E. ERICKSON, PAS, C. N. MACKEN, PAS, J. D. FOLMER, and M. P. BLACKFORD

Department of Animal Science, University of Nebraska, Lincoln 68583-0908

\section{Abstract}

One hundred sixty English-cross steers (244 kg, SD=23 kg) were used in each $y r$ of a 2-yr study to determine effects of sorting on performance, carcass characteristics, variability, and profitability in a long yearling system utilizing ranch-source calves. Steers were backgrounded during winter then grazed smooth bromegrass pastures followed by warm season native range prior to entering the feedlot in the fall. Steers were stratified by $B W$ and allotted to 1 of 4 treatments: 1) 40 head sorted by pre-grazing $B W$ where heavy steers entered the feedlot in July (PST), 2) 40 head sorted by BW entering the feedlot (FDL), 3) 60 head sorted by $B W$ and fat thickness at the end of the feeding period (IND), and 4) 20 head that were not sorted (UNS). No differences were observed for performance during backgrounding or grazing phases $(P>0.30)$. Cattle receiving PST sorting weighed less enter-

\footnotetext{
${ }^{1}$ Published, with the approval of the director, as Journal Series No. 14672, Nebraska Agricultural Research Division.

${ }^{2}$ To whom correspondence should be addressed: tklopfenstein1@unl.edu
}

ing the feedlot and consumed less feed with less feedlot $A D G$ compared to other treatments $(P<0.05)$. No differences in feed efficiencies were detected $(P=0.84)$. Cattle receiving PST sorting had greater marbling scores $(P<$ 0.05 ) and less variation in $B W$ upon feedlot entry which resulted in less variation in carcass weight compared with UNS $(P<0.05)$. Cattle sorted by $B W$ entering the feedlot tended $(P=$ $0.08)$ to have less variation in carcass weight compared with UNS. There were no differences in carcass weight or profitability when calculated on either a live or value basis. No sorting strategy increased carcass weight, reduced discounts for overweight or corpulent carcasses, or improved profitability over UNS.

Key words: sorting, yearlings, extensive forage utilization, beef production, profitability

\section{Introduction}

Value-based marketing has been implemented to encourage beef producers to provide carcasses that more closely match consumer preferences. The premise that valuebased marketing provides premiums and discounts for cattle that fit within a desired set of specifications suggests that profitability can be improved by marketing animals at an ideal time. Currently, cattle are fed to a point at which market price is equal to the cost of an additional unit of gain and marketing them before discounts are received for overweight carcasses or carcasses that are corpulent, often defined as having yield grade (YG) of 4 or higher (Fox and Perry, 1996). Adding carcass weight may improve profitability until discounts are received for 10 to $15 \%$ of the cattle in a pen (Feuz, 2002). It is difficult to market individual animals at their ideal marketing endpoint in many feeding situations because cattle are typically marketed at one time with their pen mates. This is problematic because substantial variation can occur within a feedlot pen (Cooper et al., 1999), but is important because as variation in animals increases, net returns decrease (Smith et al., 1989). To improve carcass uniformity and, presumably, profitability, researchers have investigated the possibility of sorting cattle by fatness, BW, framescore, or muscling (Trenkle and Iiams, 1997; Cooper et al., 2000; Trenkle, 2001), by ADG 
(Strasia et al., 1988), or by a combination of these characteristics (Basarab et al., 1997) Although several authors concluded that sorting achieved their goals, none of these studies directly compared sorting method to an unsorted control, and several of the studies marketed cattle at one time, forcing researchers to make conclusions retrospectively. One study that did compare sorting to an unsorted control concluded no economic benefit to sorting (Houghton et al., 1990). Additional data comparing sorting strategies to unsorted controls are needed to make objective recommendations to producers concerning sorting systems. Also, the wide range of production systems and marketing specifications will likely require that different sorting strategies be used in different situations.

The objectives of this study were to determine the effects of 3 sorting strategies on performance, carcass characteristics, animal variation, and profitability in a long yearling beef production system. Profitability was expected to improve with sorting due to an increase in carcass weight sold, a reduction in discounts received for carcasses that were overweight or corpulent, or both.

\section{Materials and Methods}

One hundred sixty mediumframed English-cross steers $(239 \mathrm{~kg}$, $\mathrm{SD}=23 \mathrm{~kg}$ in $\mathrm{yr} 1 ; 250 \mathrm{~kg}, \mathrm{SD}=22$ $\mathrm{kg}$ in yr 2) were used in a completely randomized design in each yr of a 2-yr study to determine the effects of 4 sorting strategies on performance, carcass characteristics, animal variation, and profitability in a long yearling production system that utilizes ranch-source calves. All animals were managed in accordance with protocols approved by the Animal Care and Use Committee at the University of Nebraska. A timeline of events for each sorting strategy is shown in
Figure 1. Steers were purchased from 2 ranches in the fall of each yr and were allowed to graze smooth bromegrass pastures during a 28-d adaptation period prior to beginning the trial. Steers were stratified by BW and allotted into 1 of 4 treatments to test the effects of 4 sorting strategies. Treatments were 1) 40 head sorted by pre-grazing BW where heavy steers entered the feedlot in July (PST), 2) 40 head sorted by BW entering the feedlot (FDL), 3) 60 head sorted by BW and ultrasound-measured 12th rib fat thickness at the end of the feeding period (IND), and 4) 20 head that were not sorted and served as a control (UNS). Each treatment consisted of 2 replicates. Each replicate in PST and FDL were sorted into heavy and light halves, whereas IND were sorted as individuals. Steers designated to this trial were from 2 ranch sources (2 loads/ yr to obtain sufficient numbers of cattle) to simulate a production system where all steers from a calf crop are developed into long yearlings. Steers from ranch 1 had initial BW of $261 \mathrm{~kg}(\mathrm{SD}=15 \mathrm{~kg})$ in yr 1 and $239 \mathrm{~kg}(\mathrm{SD}=21 \mathrm{~kg})$ in yr 2, and steers from ranch 2 had initial BW of $242 \mathrm{~kg}(\mathrm{SD}=24 \mathrm{~kg})$ in yr 1 and $241 \mathrm{~kg}(\mathrm{SD}=23 \mathrm{~kg})$ in yr 2. By utilizing cattle from 2 ranches of similar average BW, it is assumed that each treatment has variability in BW and potential fat depth that is typical for cattle from one ranch.

Wintering Period. Steers grazed corn residue from Nov. 30 to Feb. 8 in yr 1 and from Nov. 28 to Feb 14 in yr 2. Following removal from corn residue, they were fed ammoniated wheat straw ad libitum in a dry lot until April 21 and 20 in yr 1 and 2, respectively. Steers were given 0.049 and $0.071 \mathrm{~kg} / \mathrm{head}$ daily supplement (DM basis) while grazing corn stalks and consuming ammoniated wheat straw, respectively (Table 1 ). Steers were supplemented with $2.27 \mathrm{~kg} /$ head daily of wet corn gluten feed (WCGF, DM basis) for the entire winter period.
Summer Period. On April 21 and 20 for yr 1 and 2, respectively, cattle were implanted with RevalorG (Intervet, Millsboro, DE) and placed on smooth brome pastures near Mead, Nebraska until May 15 in yr 1 (25 d) and May 19 in yr 2 $(28 \mathrm{~d})$. Steers were then transported to native warm-season pastures near Ainsworth, Nebraska (Barta Brothers Ranch, University of Nebraska). The heavy $50 \%$ of PST was removed from grass approximately halfway through the grazing season [July 4 (50 d) and July 3 (45 d) for yr 1 and 2,respectively] and placed into the feedlot. The remaining cattle were removed from native range on Aug. 18 in yr 1 (95 d) and Aug. 29 in yr 2 (102 d). In yr 1, cattle returned to smooth bromegrass pastures to graze regrowth until Sept. 13 (26 d). In yr 2, conditions did not allow for grazing of smooth bromegrass regrowth so cattle were placed directly into the feedlot. In yr 1 the heavy-BW half of PST was on grass for $75 \mathrm{~d}$. and the remaining cattle were on grass for $146 \mathrm{~d}$. In yr 2 the heavy-BW half of the PST was on grass for $73 \mathrm{~d}$. and the remaining cattle were on grass for $130 \mathrm{~d}$. While on grass, steers were managed as one group and cattle were rotated so that forage availability did not limit steer performance.

Finishing Period. Upon entry into the feedlot, all steers were implanted with Revalor-S (Intervet, Millsboro, DE) and placed into pens. There were 10 steers per pen for all treatments except for IND which had 30 head per pen. Steers were adapted to a finishing diet in $21 \mathrm{~d}$ using 4 diets containing 45 , 35,25 , and $15 \%$ roughage fed for $3,4,7$, and 7 days, respectively. The final diet contained 7\% roughage and was formulated to contain a minimum of $12 \% \mathrm{CP}, 0.70 \% \mathrm{Ca}$, $0.35 \% \mathrm{P}, 0.60 \% \mathrm{~K}, 34 \mathrm{mg} / \mathrm{kg} \mathrm{mo}-$ nensin (Elanco Animal Health, Indianapolis, IN), and $11 \mathrm{mg} / \mathrm{kg}$ tylosin (Elanco Animal Health, Indianapolis, IN). The finishing diet con- 


\section{\begin{tabular}{lllllllllllllll}
$\mathbf{N}$ & $\mathbf{D}$ & $\mathbf{J}$ & $\mathbf{F}$ & $\mathbf{M}$ & $\mathbf{A}$ & $\mathbf{M}$ & $\mathbf{J}$ & $\mathbf{J}$ & $\mathbf{A}$ & $\mathbf{S}$ & $\mathbf{O}$ & $\mathbf{N}$ & $\mathbf{D}$ & $\mathbf{J}$ \\
\hline
\end{tabular}}

\section{UNSORTED}

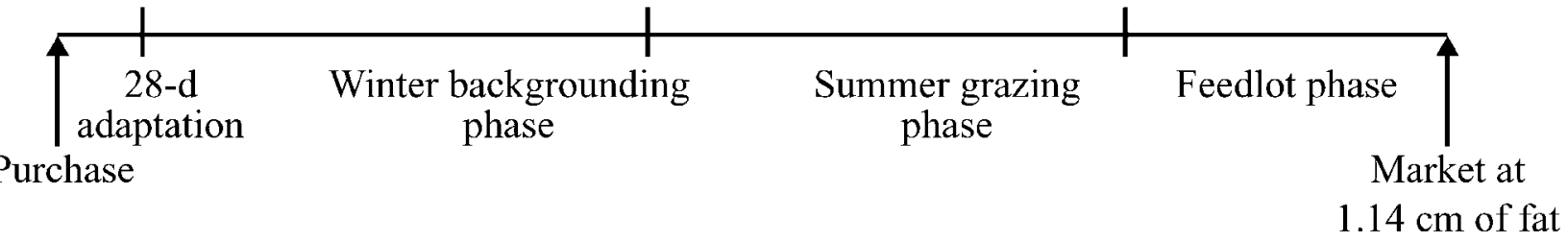

\section{PASTURE}

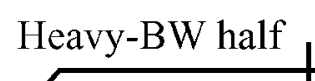

$1.14 \mathrm{~cm}$ of fat

\section{PASTURE

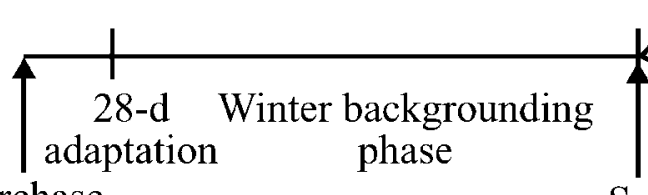 \\ Purchase \\ phase \\ Sort \\ Light-BW half \\ Summer grazing \\ phase \\ Sort \\ FEEDLOT \\ Purchase

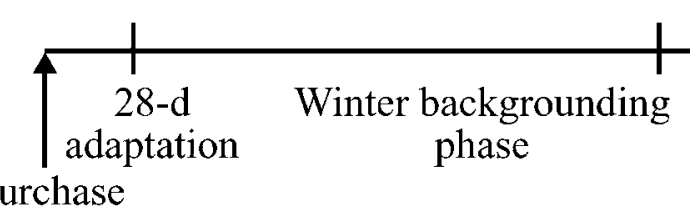

\section{INDIVIDUAL}

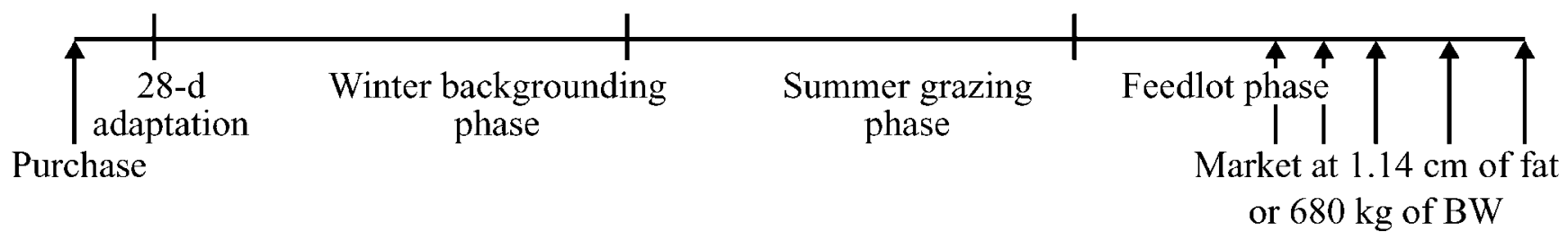

Figure 1. Timeline of events for 4 sorting strategies in a long yearling system. Letters at top correspond to month of year. Dates are approximate. UNS = no sorting; PST = sorted based on pre-grazing BW;FDL = sorted based on BW entering the feedlot; IND = sorted by $B W$ and fat thickness at the end of the feeding period.

tained 40\% WCGF, 48\% high moisture corn, $7 \%$ alfalfa, and 5\% supplement (DM basis; Table 2). Initial BW for the winter, summer, and finishing periods were an average of 2 weights taken on consecutive days following a 4-d period of limit feeding at $2 \% \mathrm{BW}$ to equalize gut fill. The limit-fed diet consisted of $47.5 \%$ WCGF, $47.5 \%$ alfalfa hay, and $5 \%$ supplement.

Each treatment had an individual marketing strategy based on fat thickness or a combination of fat thickness and BW. Fat thickness was measured between the 12th and 13th rib with an Aloka 500V model ultrasound machine (Corometrics Medical Systems, Wallingford, CT) attached to a $20-\mathrm{cm}$ linear array transducer. Animal hide was curried to remove loose material if necessary and mineral oil was applied to the region to ensure maximal acoustical contact. The PST treatment was marketed equally in 2 groups (light BW and heavy BW) when 12th rib fat thickness (FT) averaged $1.14 \mathrm{~cm}$ for each group. The FDL treatment was also marketed equally in 2 groups (light BW and heavy BW), but dif- ferent marketing strategy was used. The target market endpoint for the trial was $1.14 \mathrm{~cm}$ FT. However, the heaviest steers may result in overweight carcasses prior to reaching the target FT. Additionally, it may be beneficial to continue to add carcass weight to lighter steers beyond the target FT but before reaching a YG 4 carcass. Therefore, the heavyBW half was marketed when the group averaged $1.00 \mathrm{~cm}$ FT to avoid overweight carcasses, and the light-BW half was marketed when the group averaged $1.27 \mathrm{~cm}$ FT to allow them to gain additional car- 
TABLE 1. Composition and ingredient prices for winter supplements (DM basis).

\begin{tabular}{lccr} 
Item & Corn stalks $^{\mathbf{a}}$ & Wheat $^{\text {straw }^{\mathbf{b}}}$ & Cost $^{\mathbf{c}}$ \\
\hline Limestone & 51.8 & 55.8 & 0.03 \\
Salt & 35.2 & 32.6 & 0.12 \\
Trace mineral premix $^{\mathrm{d}}$ & 5.9 & 5.4 & 0.88 \\
Vitamin premix $^{\mathrm{e}}$ & 3.5 & 3.3 & 1.11 \\
Rumensin $^{f}$ & 1.9 & 1.3 & 15.66 \\
Selenium premix $^{\mathrm{g}}$ & 1.7 & 1.6 & 0.18
\end{tabular}

a Supplements fed while grazing corn stalk residue $(0.049 \mathrm{~kg} /$ head per d; DM basis).

${ }^{\text {b}}$ Supplements fed while consuming wheat straw in drylot $(0.071 \mathrm{~kg} /$ head per d; DM basis).

'Ingredient costs were similar for both supplements ( $\$ / \mathrm{kg} ; \mathrm{DM}$ basis).

dPremix contained $10 \% \mathrm{Mg}, 6 \% \mathrm{Zn}, 4.5 \% \mathrm{Fe}, 2 \% \mathrm{Mn}, 0.5 \% \mathrm{Cu}, 0.3 \% \mathrm{I}$, and $0.05 \%$ Co.

ePremix contained 1,500 IU of vitamin A, 3,000 IU of vitamin D, and 3.7 IU of vitamin E/g.

fPremix contained $176 \mathrm{~g} / \mathrm{kg}$ monensin (Elanco Animal Health, Indianapolis, IN).

gPremix contained $0.06 \%$ Se. cass weight. The average market FT of FDL was intended to be $1.14 \mathrm{~cm}$
FT so that treatment comparisons could be made at a constant car-

\section{TABLE 2. Composition and ingredient costs of finishing diet. ${ }^{a}$}

\begin{tabular}{|c|c|c|}
\hline Item & (\% DM) & $\operatorname{Cos}^{b}$ \\
\hline High moisture corn & 48.0 & 0.12 \\
\hline Wet corn gluten feed & 40.0 & 0.12 \\
\hline Alfalfa & 7.0 & 0.09 \\
\hline Supplement composition & 5.0 & 0.22 \\
\hline Fine ground corn & 2.37 & 0.12 \\
\hline Limestone & 1.89 & 0.03 \\
\hline Salt & 0.30 & 0.12 \\
\hline Ammonium chloride & 0.25 & 0.73 \\
\hline Tallow & 0.10 & 0.47 \\
\hline Trace mineral premix ${ }^{c}$ & 0.05 & 0.88 \\
\hline Rumensin $^{d}$ & 0.02 & 15.66 \\
\hline Tylan ${ }^{\mathrm{e}}$ & 0.01 & 14.22 \\
\hline Vitamin premix ${ }^{f}$ & 0.01 & 1.12 \\
\hline
\end{tabular}

a Diet was formulated to contain a minimum of $12 \% \mathrm{CP}, 0.70 \% \mathrm{Ca}, 0.35 \% \mathrm{P}$, and $0.70 \% \mathrm{~K}$.

${ }^{b}$ Ingredient cost, $\$ / \mathrm{kg}$ (DM basis).

CPremix contains $10 \% \mathrm{Mg}, 6 \% \mathrm{Zn}, 4.5 \% \mathrm{Fe}, 2 \% \mathrm{Mn}, 0.5 \% \mathrm{Cu}, 0.3 \% \mathrm{I}$, and $0.05 \%$ Co.

dPremix contains $176 \mathrm{~g} / \mathrm{kg}$ monensin (Elanco Animal Health, Indianapolis, IN). ePremix contains $88 \mathrm{~g} / \mathrm{kg}$ tylan (Elanco Animal Health).

${ }^{f}$ Premix contains $1,500 \mathrm{IU}$ vitamin $\mathrm{A}, 3,000 \mathrm{IU}$ vitamin $\mathrm{D}$, and $3.7 \mathrm{IU}$ vitamin $\mathrm{E} /$ g. cass composition endpoint. The IND treatment was marketed as individuals in 4 kill dates in yr 1 and 5 kill dates in yr 2. Fat thickness was measured by ultrasound and BW was measured every 2 wk once the cattle were on feed for approximately $50 \mathrm{~d}$. Cattle were marketed once they reached approximately $1.14 \mathrm{~cm}$ FT or $680 \mathrm{~kg}$ shrunk BW (4\% shrink), whichever came first. Ultrasound was also used to determine FT of other treatments as estimated marketing time neared, but was not collected at regular intervals as was the case with IND.

Hot carcass weights (HCW) were collected on all steers at the time of slaughter. Marbling score (MARB), longissimus area (LMA), YG and FT were measured following a 72-h chill. Marbling scores and YG were called by USDA personnel at the abattoir.

Economic Analysis. Jordon (2000) did an extensive economic analysis of a production system similar to the one investigated herein. The economic analysis described here is adapted from his analysis. Input costs were similar across treatments. For initial steer cost, average weight of a replicate was multiplied by the USDA Nebraska auction market 1991 to 2000 average November calf price $(\$ 84.49 / 45 \mathrm{~kg}$ ) for 227 to $272 \mathrm{~kg}$ feeder calves (Feuz et al., 2001). Interest was charged on initial steer cost for the entire ownership. Interest was charged at a simple annual rate of $9.8 \%$ for all costs, corrected for days.

Winter Period. Steers were charged $\$ 8.33 /$ head for health and processing costs during the winter period and interest accrued on these costs for the remainder of ownership. The cost of corn residue was charged at a rate of $\$ 0.12$ / steer daily while steers grazed corn stalks. Steers were given $0.049 \mathrm{~kg} /$ steer daily of a mineral supplement that cost $\$ 446.24$ per metric ton ( $t$; DM basis; Table 1). Interest was charged for half of the stalk-graz- 
ing period plus the remainder of ownership for corn residue and mineral supplement. Ammoniated wheat straw was priced at $\$ 44.00 / \mathrm{t}$ (as-is). Wheat straw intake was assumed to be $5.8 \mathrm{~kg} / \mathrm{steer}$ daily (asis) based on observations of Jordon (2000). Cattle were also given $0.071 \mathrm{~kg} /$ steer daily of a mineral supplement that cost $\$ 338.82 / \mathrm{t}$ (DM basis; Table 1). Interest was charged for wheat straw cost and mineral supplement for half the period the steers were in the dry lot plus the remainder of ownership.

Steers were supplemented with $2.27 \mathrm{~kg} / \mathrm{steer}$ daily (DM basis) of WCGF for the entire winter period at a cost of $\$ 113.28 / \mathrm{t}$ [DM basis; equal to a corn price of $\$ 0.097 / \mathrm{kg}$ (as-is)]. Interest was charged on the WCGF for half the winter period and the remainder of ownership. Yardage was charged at a rate of $\$ 0.12 /$ steer daily while on stalks and $\$ 0.24 /$ steer daily while in the dry lot. Yardage charges include delivery of the WCGF. Interest was charged on yardage for half the respective period and the remainder of ownership. In yr 2, snowfall required that steers be supplemented with $1.9 \mathrm{~kg} / \mathrm{steer}$ daily of a storm ration that cost $\$ 0.12 /$ steer daily for $38 \mathrm{~d}$. Interest for the cost of the storm ration was charged to the steers for half of the $38 \mathrm{~d}$ period plus the remainder of ownership.

A breakeven price was calculated for the winter period by dividing total winter costs by final winter BW for each replicate. Total winter costs included a $1 \%$ death loss, steer purchase price, as well as health, feed, yardage, and interest charges. Price paid for the steers at the end of the winter period was the USDA Nebraska auction market 1992 to 2001 average feeder steer price for 318 to $363 \mathrm{~kg}$ steers for the month of April (\$77.49/45 kg; Feuz et al., 2001). Profit or loss was determined for the winter period by multiplying the difference in price paid and breakeven price by the mean BW of the replicate.
Summer Period. Summer grazing costs were charged at a rate of $\$ 0.60 /$ steer daily based on the cost of pasture rent in northeast Nebraska. (Johnson, 2001). Total grazing costs included all costs for the winter period, $\$ 8.33 /$ head for health, $0.5 \%$ death loss, and grazing and interest costs. A breakeven price was calculated for the grazing period by dividing the sum of these costs by the mean BW for each replicate. Similar to the winter period, price paid following the summer period was the average USDA Nebraska auction market feeder steer price for 409 to $455 \mathrm{~kg}$ feeder steers from 1996 to 2001 (Feuz et al., 2001). For UNS, FDL, and IND, all cattle were removed from grass in August so price paid for those treatments was the average August price $(\$ 74.83 / 45 \mathrm{~kg})$. The PST treatment required some cattle be removed from grass in July and some in August. Price paid for each replicate in this treatment was a weighted average of the July $(\$ 75.77 / 45 \mathrm{~kg})$ and August prices so that the price paid for each replicate reflected the number of cattle sold in each of those 2 months. Profit or loss was calculated by multiplying the difference of price paid and breakeven price by the mean BW of the replicate.

Finishing period. Finishing costs included feed and yardage. Feed costs were determined by multiplying the cost of the finishing diet ( $\$ 123.05 / t$; DM basis; Table 2) by the mean DMI for each replicate. Feedlot yardage was charged at a rate of $\$ 0.30 /$ steer daily. Interest was charged on feed and yardage costs for half of the finishing period. Total steer cost was the sum of steer, winter, and summer costs plus finishing costs, which included health $(\$ 8.33 /$ head), $0.5 \%$ death loss, feed, and yardage costs. No charges for ultrasound were applied. Slaughter breakeven was calculated by dividing total costs by mean BW. Profit was calculated two ways. First, profit was calcu- lated using an average live cattle price from the months of October $(\$ 67.88 / 45 \mathrm{~kg})$, November $(\$ 69.07 /$ $45 \mathrm{~kg})$, and December $(\$ 67.88 / 45$ $\mathrm{kg}$ ) from 1992 to 2001 (Feuz et al., 2001). Actual price paid for each replicate was a weighted average based on the number of cattle sold in each of the 3 months for each replicate. Second, profit was calculated by selling the cattle on the rail in a value-based market that rewards for high-marbling cattle. The grid utilized is presented in Table 3 and was based on Feuz (2002) who created the grid from industry averages from 1994 to 2000. The grid was changed so that premiums and discounts received for marbling were based on MARB rather than percent choice. This was done because of the small and varying numbers of cattle in each replicate. Because of this, a few differences in individual's grading choice can have large impacts on the percent choice of the replicate. Thus, using the average MARB for each replicate is a more realistic comparison. Premiums and discounts for marbling were based on the choice-select spread for the months of October $(\$ 9.19 / 45 \mathrm{~kg})$, November $(\$ 9.80 / 45 \mathrm{~kg})$, and December $(\$ 8.00 / 45 \mathrm{~kg})$ from $1992-2002$ (Feuz et al., 2001). The actual choice-select spread for each replicate was calculated using a weighted average based on the number of cattle marketed in each of the 3 mo. A MARB of small ${ }^{00}$ received no premium or discount. Premiums and discounts were calculated by multiplying the choice-select spread by 100 units above or below small ${ }^{00}$ (premiums for MARB above small ${ }^{00}$ and discounts for MARB below small ${ }^{00}$ ). For example, if the choice-select spread was $\$ 10.00 / 45 \mathrm{~kg} \mathrm{HCW}$, an animal with a MARB of small ${ }^{50}$ would receive a \$5.00/45 kg HCW premium, and an animal with a MARB of slight ${ }^{50}$ would receive a $\$ 5.00 / 45$ kg HCW discount. The base price used was the average Nebraska 
TABLE 3. Marketing grid used for economic analysis.

\begin{tabular}{|c|c|}
\hline Item & Premium or discount $^{a}$ \\
\hline \multicolumn{2}{|l|}{ Base Price } \\
\hline October & 107.43 \\
\hline November & 109.57 \\
\hline December & 109.58 \\
\hline Marbling score ${ }^{b}$ & $\begin{array}{l}\left.\text { (marbling score }-500^{c}\right) \times \\
(\text { choice-select spread } / 100)\end{array}$ \\
\hline \multicolumn{2}{|l|}{ Choice-select spread } \\
\hline October & 9.19 \\
\hline November & 9.80 \\
\hline December & 8.00 \\
\hline Yield grade 1 & 1.00 \\
\hline Yield grade 2 & 1.00 \\
\hline Yield grade 3 & 0.00 \\
\hline Yield grade 4 & -12.00 \\
\hline Yield grade 5 & -17.00 \\
\hline Heavy and light carcasses ${ }^{d}$ & -15.00 \\
\hline \multicolumn{2}{|c|}{ a $\$ / 45 \mathrm{~kg}$ of carcass weight. } \\
\hline \multicolumn{2}{|c|}{$\begin{array}{l}\text { b Premium or discount for marbling score was calculated using a sliding scale } \\
\text { where a marbling score of } 500 \text { received } \$ 0 \text {, and premiums or discounts for } \\
\text { marbling scores above and below } 500 \text { were allocated based on the choice- } \\
\text { select spread for the month in which the cattle were sold. }\end{array}$} \\
\hline \multicolumn{2}{|c|}{${ }^{\mathrm{M}}$ Marbling score $400=$ slight $^{00}, 500=$ small $^{00}$, etc. } \\
\hline \multicolumn{2}{|c|}{${ }^{\mathrm{d}}$ Heavy carcasses $>431 \mathrm{~kg}$, light carcasses $<250 \mathrm{~kg}$. } \\
\hline
\end{tabular}

dressed fed cattle price for October $(\$ 107.43 / 45 \mathrm{~kg})$, November $(\$ 109.57 / 45 \mathrm{~kg})$, and December $(\$ 109.58 / 45 \mathrm{~kg})$ from 1992 to 2001 (Feuz et al., 2001). Actual base price paid for each replicate was calculated using a weighted average of the number of cattle sold in each of the 3 months for each replicate.

Prices for supplemental ingredients used in the winter mineral supplements (Table 1), and finishing diet (Table 2) were based on actual prices paid for those ingredients by the University of Nebraska Feed Mill over the period of $1 \mathrm{yr}$ with a 5\% handling fee. High moisture corn and WCGF were charged on an equal dry basis at a price of $\$ 0.11 / \mathrm{kg}(\mathrm{DM})$. This price is based on a 10-yr average corn price for Nebraska (Wellman, 1998) and includes a $10 \%$ shrink, processing, and handling fee. Alfalfa in the finishing diet was priced based on the 10 -yr average price in Nebraska of \$71.21/t (DM; Wellman, 1998) along with an $\$ 11.00 / \mathrm{t}$ markup for grinding, handling, and shrink.

Statistical Analysis. Data were analyzed as a completely randomized design using the mixed procedure of SAS (SAS Inst. Inc., Cary, $\mathrm{NC)}$ with $\mathrm{yr}$ and $\mathrm{yr} \times$ treatment included as random variables. Degrees of freedom were calculated using the Kenward-Roger option in SAS. Also, since there were different numbers of cattle in each treatment, the weight option was used so each replicate was weighted based on the number of head in that replicate. Replicate rather than pen was the experimental unit because each replicate in PST and FDL included 2 pens that were marketed at different times. For these 2 treatments, replicate was calculated by averaging the 2 pens. Effect of treatment was significant when $P<$ 0.05 as detected by an F-test. When the F-test was significant, least square means of treatments were separated using a t-test when $P<$ 0.05 .

Least squares means for one standard deviation of winter initial BW (WIWT), grass initial BW (GIWT), feedlot initial BW (FIWT), HCW, and FT are reported to quantify treatment effects on variability. Differences in least squares means were determined from analysis of the log base 10 transformation of the standard deviations. Least squares means and standard errors were reported from the transformation of the log base 10 numbers into standard deviations.

\section{Results and Discussion}

Performance data are presented in Table 4 . No differences $(P=$ 0.80 ) were observed for initial weight during the winter period for any treatment. There were no differences $(P>0.26)$ in initial BW or ADG across treatments during the summer period. Cattle in the PST sort were of lighter weight $(P<$ $0.01)$ on average when entering the feedlot because the heavy half of each replicate grazed fewer days. As a result of this, they also consumed less DM per day $(P<0.01)$ and ADG was reduced $(P=0.05)$ through the feeding period. Reduced DMI may also be related to time of year as these cattle were fed in the feedlot from mid-July to October and endured warmer temperatures compared to other treatments. There were no differences in feed efficiency $(P=0.85)$ among treatments suggesting gain differences were related to DMI.

Carcass data are presented in Table 5. In yr 1, the heavy half of PST (those that were removed from grass in July) was marketed at 1.40 $\mathrm{cm}$ FT rather than $1.14 \mathrm{~cm}$ FT. This accounted for $25 \%$ of the observations in this treatment. In order to make comparisons to other treatment on an equal fat basis, FT, days on feed, HCW, MARB, and percent overweight were adjusted so that the average fat thickness of 
TABLE 4. Effects of sorting strategy on performance of long yearlings.

\begin{tabular}{|c|c|c|c|c|c|}
\hline Item & UNS $^{a}$ & PST & FDL & IND & SEM \\
\hline \multicolumn{6}{|l|}{ Winter } \\
\hline Initial BW, kg & 244 & 244 & 245 & 243 & 6 \\
\hline $\mathrm{ADG}, \mathrm{kg}$ & 0.64 & 0.64 & 0.65 & 0.67 & 0.13 \\
\hline \multicolumn{6}{|l|}{ Summer } \\
\hline Initial BW & 336 & 336 & 338 & 339 & 13 \\
\hline ADG & 0.76 & 0.80 & 0.78 & 0.79 & 0.02 \\
\hline \multicolumn{6}{|l|}{ Feedlot } \\
\hline Initial BW, kg & $442^{\mathrm{b}}$ & $421^{\mathrm{c}}$ & $446^{\mathrm{b}}$ & $447^{b}$ & 10 \\
\hline$A D G, \mathrm{~kg}$ & $2.15^{\mathrm{b}}$ & $1.99^{c}$ & $2.08^{b}$ & $2.10^{\mathrm{b}}$ & 0.05 \\
\hline $\mathrm{DMI}, \mathrm{kg} / \mathrm{d}$ & $14.2^{\mathrm{b}}$ & $13.2^{\mathrm{C}}$ & $14.0^{\mathrm{b}}$ & $14.0^{\mathrm{b}}$ & 0.1 \\
\hline Gain/feed & 0.151 & 0.150 & 0.150 & 0.148 & 0.004 \\
\hline Slaughter BW, $\mathrm{kg}^{\mathrm{d}}$ & 619 & $626(617)$ & 632 & 628 & 9 \\
\hline
\end{tabular}

${ }^{\mathrm{a} U N S}=$ no sorting; $\mathrm{PST}=$ sorted based on pre-grazing BW; FDL = sorted based on BW entering the feedlot; IND = sorted by BW and fat thickness at the end of the feeding period.

$b, c$ Means within a row with unlike superscripts differ $(P<0.05)$.

${ }^{\mathrm{d} C}$ Calculated from hot carcass weight adjusted to a common dressing percentage (62.5). In yr 1, the heavy-BW half of PST was marketed at $1.40 \mathrm{~cm}$ fat thickness rather than $1.14 \mathrm{~cm}$ fat thickness. This accounts for $25 \%$ of the observations in this treatment. The BW in parentheses is the mean value after adjusting the $25 \%$ that were marketed at $1.40 \mathrm{~cm}$ to the target $1.14 \mathrm{~cm}$ fat thickness. Adjustment does not change statistical significance.

the heavy half of the PST treatment was $1.14 \mathrm{~cm}$. Fat thickness was adjusted by a linear fattening rate of $0.12 \mathrm{~mm} / \mathrm{d}$. This rate of fattening was arrived at by calculating the fattening rate for similar cattle that were serially slaughtered approximately $65 \mathrm{~d}$ apart (Vieselmeyer et al., 1996). This was compared to the fattening rate of cattle that were progressively measured with ultrasound during the last 4 wk of the feeding period (MacDonald, 2002). There was close agreement between the 2 methods on the rate of fattening for long yearling cattle during the end of the feeding period. Others have re-

\section{TABLE 5. Effects of sorting strategy on carcass characteristics of long yearlings.}

\begin{tabular}{|c|c|c|c|c|c|}
\hline Item & UNS $^{\mathrm{a}}$ & PST & FDL & IND & SEM \\
\hline Hot carcass weight, $\mathrm{kg}^{\mathrm{b}}$ & 387 & $391(386)$ & 395 & 393 & 5 \\
\hline Fat thickness, $\mathrm{cm}^{\mathrm{b}}$ & 1.16 & $1.23(1.17)$ & 1.16 & 1.13 & 0.03 \\
\hline $\mathrm{LMA}, \mathrm{cm}^{2, \mathrm{c}}$ & 103.4 & 96.9 & 101.1 & 101.2 & 8.2 \\
\hline Called yield grade ${ }^{d}$ & $2.60^{\mathrm{e}}$ & $2.65^{\mathrm{e}}$ & $2.48^{\mathrm{f}}$ & $2.43^{\mathrm{f}}$ & 0.08 \\
\hline Calculated yield grade ${ }^{\text {bg }}$ & 2.27 & $2.66(2.55)$ & 2.45 & 2.37 & 0.42 \\
\hline Marbling score ${ }^{\text {bh }}$ & $505^{\mathrm{e}}$ & $535^{f}\left(528^{f}\right)$ & $505^{\mathrm{e}}$ & $509^{e}$ & 6 \\
\hline Percent overweight ${ }^{\mathrm{b}}$ & 8 & $5(0)$ & 5 & 8 & 0.04 \\
\hline
\end{tabular}

${ }^{a}$ UNS = no sorting; PST = sorted based on pre-grazing BW; FDL = sorted based on BW entering the feedlot; IND = sorted by BW and fat thickness at the end of the feeding period.

${ }^{b}$ In $\mathrm{yr} 1$, the heavy-BW half of PST was marketed at $1.40 \mathrm{~cm}$ fat thickness rather than $1.14 \mathrm{~cm}$ fat thickness. This accounts for $25 \%$ of the observations for this treatment. The values in parentheses are the mean values after adjusting the $25 \%$ that were marketed at $1.40 \mathrm{~cm}$ to the target $1.14 \mathrm{~cm}$ fat thickness. Adjustment does not change statistical significance for any measurement.

'Longissimus area.

${ }^{d}$ Yield grade called by USDA personnel at abattoir.

${ }^{e, f}$ Means within a row with unlike superscripts differ $(P<0.05)$.

gYield grade calculated from measurements of fat thickness, hot carcass weight, and longissimus area. Kidney, pelvic, and heart fat was assumed to be $2.5 \%$ for all steers. 
TABLE 6. Effects of sorting strategy on SD of weight and fat thickness in yearlings. ${ }^{\text {a }}$

\begin{tabular}{|c|c|c|c|c|c|}
\hline Item & UNS $^{b}$ & PST & FDL & IND & SEM \\
\hline WIWT, $\mathrm{kg}^{\mathrm{c}}$ & 25 & 21 & 22 & 23 & 1 \\
\hline GIWT, $\mathrm{kg}^{\mathrm{d}}$ & 32 & 28 & 28 & 28 & 1 \\
\hline FIWT, $\mathrm{kg}^{\mathrm{e}}$ & $32^{f}$ & $17^{9}$ & $28^{f}$ & $30^{f}$ & 1 \\
\hline Carcass weight, $\mathrm{kg}^{\mathrm{f}}$ & $25^{9}$ & $22\left(19^{h}\right)$ & $21^{\text {gh }}$ & $27^{9}$ & 1 \\
\hline Fat thickness, $\mathrm{cm}^{f}$ & 0.19 & $0.32(0.30)$ & 0.31 & 0.23 & 1.32 \\
\hline
\end{tabular}

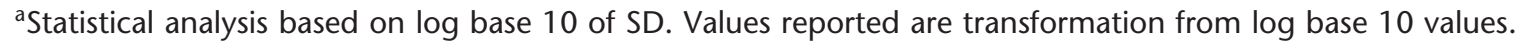

${ }^{\text {bUNS }}=$ no sorting; PST = sorted based on pre-grazing BW; FDL = sorted based on BW entering the feedlot; IND = sorted by $B W$ and fat thickness at the end of the feeding period.

'Winter initial BW.

${ }^{\mathrm{d}}$ Grass initial BW.

eFeedlot initial BW.

fIn yr 1, the heavy-BW half of PST was marketed at $1.40 \mathrm{~cm}$ fat thickness rather than $1.14 \mathrm{~cm}$ fat thickness. This accounts for $25 \%$ of the observations for this treatment. The values in parentheses are the mean values after adjusting the $25 \%$ that were marketed at $1.40 \mathrm{~cm}$ to the target $1.14 \mathrm{~cm}$ fat thickness. Statistical differences for carcass weight are for adjusted values. Unadjusted values for carcass weight are not different. Adjustment does not change statistical significance for fat thickness.

g,h Means within a row with unlike superscripts differ $(P<0.05)$.

ported fattening rates ranging from $0.03 \mathrm{~mm} / \mathrm{d}$ (Trenkle and Iiams, 1997) to $0.09 \mathrm{~mm} / \mathrm{d}$ (Van Koevering et al., 1995). Fattening rate can be influenced by genetic fattening potential, implant strategies, and number of days encompassed in the calculation. Days on feed were adjusted back by $21 \mathrm{~d}$ for the heavy-BW half of the PST treatment and carcass weight was adjusted by using individual ADG multiplied by a constant dressing percent of $62.5 \%$. Klopfenstein et al. (2000) reported that steers sired by Angus bulls deposited intramuscular fat at a rate of 1.48 units/d $\left(200=\right.$ slight $^{00} ; 300=$ small $\left.^{00}\right)$. Using this rate of marbling, all steers receiving adjustments were assigned a MARB that was reduced by 31 units $\left(400=\right.$ slight $^{00} ; 500=$ small $\left.^{00}\right)$.

Adjusted data are provided in parenthesis following the unadjusted data for all affected measurements in Tables 4 to 6 . Adjustments rarely changed statistical significance. However, for measurements where adjustment did change statistical significance, authors suggest that adjusted data more accurately reflects treatment effects because comparisons are made at an equal fat endpoint (Klopfenstein et al., 2000). There were no differences $(P$ $>0.59$ ) in HCW, LMA, or FT across treatments regardless of adjustment. The UNS and PST treatments had increased $(P<0.01)$ called YG scores as compared to FDL or IND. The heavy-BW half of PST treatment were sold at $1.40 \mathrm{~cm}$ fat thickness rather than $1.14 \mathrm{~cm}$ and $Y G$ scores called by USDA personnel could not be adjusted for this treatment. Thus, this difference may be due to marketing date rather than to treatment differences. To account for differences in marketing date, YG was calculated from measurements of HCW, FT, and LMA. Kidney, pelvic, and heart fat was assumed to be $2.5 \%$ in all steers. Calculated YG generally agreed with YG called by USDA personnel, but differences due to treatment were not significant $(P=0.56)$. Authors suggest that marketing a portion of PST cattle at a greater FT artificially increased YG called by USDA personnel. Cattle in the PST treatment had greater $(P<0.01)$ MARB than cattle in other treatments, regardless of adjustment. This is likely due to additional days on feed (ap- proximately 25 d) required by steers removed midway through the summer. There were no differences $(P=0.65)$ in percent overweight carcasses (HCW $>430 \mathrm{~kg}$ ), regardless of adjustment. Although the objective of selling carcasses at a minimum average fat depth of $1.14 \mathrm{~cm}$ was achieved, the small number of overweight carcasses and lack of carcasses with YG 4 or greater ( 2 in the study) suggest the target marketing endpoint could have been extended.

Standard deviations for WIWT, GIWT, FIWT, HCW, and FT are presented in Table 6 . One goal of this study was to determine if the tested sorting strategies could reduce variation in HCW and FT. As expected, there were no differences in variation in WIWT or GIWT. The PST treatment consistently had less variability in weight entering the feedlot compared to other treatments. Also, the heavy-BW and light-BW halves of each PST replicate had similar weights entering the feedlot (420 vs. $422 \mathrm{~kg}$, respectively). This further suggests that variation in FIWT was successfully reduced with the PST strategy. Although not different from FDL, 
PST did have less variation in carcass weight compared to UNS or IND when data were adjusted to a common FT. Additionally, FDL tended to have less variation than IND $(P=0.06)$ or UNS $(P=0.08)$. It is surprising that IND had variability in carcass weight equal to that of UNS since it was expected that IND would have the greatest possibility of marketing the individual animals closest to their ideal marketing date. It is possible that because there were fewer head in UNS, there was less opportunity for variation compared to other treatments, which had greater numbers of cattle per replicate. Ten head per replicate were used in UNS so additional animals could be used for IND. This reallocation in animal resources was deemed necessary so that adequate numbers were available in IND for several marketing dates, allowing every animal to be marketed as close to the target FT or BW as possible. It is also possible that IND had more variation than PST or FDL because each animal in the IND sort was in fact marketed closer to their ideal marketing endpoint; animals that fatten quickly had lesser carcass weights and animals that fatten slowly had heavier carcass weights, resulting in more variation in HCW. Economic analyses are shown in Table 7 and are based on adjusted data for PST. There were no differences in breakeven or profit or loss during the winter phase, which was expected since all cattle were treated as one group during the winter phase. The reduction in grass final BW as a result of removing half of PST increased breakeven price and decreased profit after the summer phase even though cattle in this treatment were owned for fewer days. No differences were found in breakevens, profits from the live marketing scenario, or profits from the grid marketing scenario. The PST treatment received more premium than other treatments because of additional MARB and no overweight carcasses. There were no differences in profit even though there were differences in premiums and discounts. This suggests that premiums received for MARB were offset by HCW. Feuz (2002) suggested that adding HCW and MARB is economically beneficial even while receiving discounts for up to 10 to $15 \%$ of the cattle in a pen. Reductions in overweight or corpulent carcasses were expected to be a source of improved profitability in the study. The fact that few discounts were received by any treatment suggests that all cattle could have been on feed longer to gain additional BW and marbling. Since the nature of cattle feeding encourages animals to remain on feed until a threshold of BW, fat, or both is attained, differences in these sorting strategies may not have been allowed to manifest themselves because most cattle did not reach the threshold. Additionally, reduced variability in HCW by PST sorting suggests more uniform cattle were marketed, and perhaps the average HCW could be expected to increase compared with unsorted cattle as 10 to $15 \%$ of cattle cross the threshold as suggested by Feuz (2002).

The lack of improved profitability from these data demonstrates the need for producers to implement low-cost sorting strategies. The FDL and IND treatments were similar across all measurements taken in the current study. Although IND cattle were not charged for ultrasound measurements in the economic analysis, there is certainly a cost to utilizing the technology. The cost of the machine is nominal on a per head basis if every animal in the feedlot is measured. The greater costs are likely those that are more difficult to measure. Skilled labor required to operate the machine and interpret the images adds cost to the system as does the additional time required to capture the image at the chute. Taking multiple measures at the end of the feeding period, as was done in the IND treatment, is possibly the most costly part of utilizing the technology due to the potential for added stress on the animals. Conversely, the FDL treatment could be utilized with little additional cost because implementation of this strategy requires only a chute scale and means to sort cattle coming out of the chute, both of which many feedlots have in place. While the FDL treatment could be implemented at little cost in many feeding operations, it did not achieve our sorting objectives of increasing HCW, reducing discounts, and improving profitability. However, it did tend to reduce the variability in $\mathrm{HCW}(P=0.08)$. This sorting strategy may be more successful if cattle were sorted into 3 rather than 2 marketing groups. When a normally distributed population is divided into 2 halves, such as was the case in this study, there is likely little difference between the heaviest steers in the "light" sort, and the lightest steers in the "heavy" sort. Additionally, success achieved from sorting based on BW will likely be realized by marketing the heaviest animals early to reduce discounts, and feeding the lightest animals longer to allow time for additional HCW. Therefore, we hypothesize that sorting yearlings into 3 marketing groups (heaviest 25\%, average 50\%, and lightest 25\%) at the time steers enter the feedlot may allow the objectives of this study to be realized.

\section{Implications}

No sorting strategy increased HCW, reduced discounts for overweight or corpulent carcasses, or improved profitability compared to UNS, demonstrating a need for low-cost sorting strategies. These data do not negate the potential usefulness of sorting because treatments may have benefited from additional time on feed, and cattle 
TABLE 7. Effects of sorting strategy on costs, breakeven prices, and profitability in long yearlings.

\begin{tabular}{|c|c|c|c|c|c|}
\hline Item & UNS $^{a}$ & PST & FDL & IND & SEM \\
\hline Steer cost, $\$$ & 454.34 & 454.56 & 456.25 & 453.08 & - \\
\hline Health $^{\mathrm{b}}$ & 27.44 & 27.34 & 27.49 & 27.46 & - \\
\hline \multicolumn{6}{|l|}{ Winter costs, $\$$} \\
\hline Feed & 70.95 & 70.95 & 70.95 & 70.95 & - \\
\hline Yardage & 26.52 & 26.52 & 26.52 & 26.52 & - \\
\hline Final winter weight, $\mathrm{kg}$ & 336 & 336 & 338 & 339 & 13 \\
\hline Winter breakeven ${ }^{c}$ & 78.81 & 78.92 & 78.64 & 78.11 & 0.39 \\
\hline Winter profit or loss ${ }^{d}$ & -8.62 & -9.42 & -7.52 & -3.62 & 453 \\
\hline \multicolumn{6}{|l|}{ Summer costs, $\$$} \\
\hline Grazing & 80.84 & 61.18 & 80.84 & 80.84 & - \\
\hline Final grass BW, kg & $442^{d}$ & $421^{\mathrm{e}}$ & $446^{\mathrm{d}}$ & $447^{d}$ & 10 \\
\hline Summer breakeven ${ }^{\mathrm{e}}$ & $72.00^{\text {ef }}$ & $72.98^{\mathrm{e}}$ & $71.59^{f}$ & $69.89^{f}$ & 2.75 \\
\hline Summer profit or loss & $28.00^{\text {ef }}$ & $22.18^{\mathrm{e}}$ & $32.29^{\mathrm{gf}}$ & $37.99^{f}$ & 27.74 \\
\hline \multicolumn{6}{|l|}{ Finishing costs, $\$$} \\
\hline Yardage & 25.02 & 30.02 & 27.32 & 26.98 & - \\
\hline Feed & 149.51 & 174.38 & 157.56 & 162.53 & - \\
\hline Total costs, $\$$ & 903.37 & 911.42 & 917.31 & 917.81 & - \\
\hline Slaughter weight, kg & 619 & 617 & 632 & 628 & 9 \\
\hline Breakeven $^{\mathrm{h}}$ & 66.31 & 67.12 & 65.92 & 66.41 & 1.60 \\
\hline Live profit/lossi & 30.58 & 18.47 & 31.46 & 26.76 & 31.46 \\
\hline Premium/discount & $-0.28^{\mathrm{d}}$ & $2.75^{\mathrm{e}}$ & $0.05^{\mathrm{d}}$ & $-0.01^{d}$ & 0.64 \\
\hline Grid profit/lossk & 28.01 & 37.31 & 36.22 & 28.08 & 22.66 \\
\hline
\end{tabular}

${ }^{a}$ UNS = no sorting; PST = sorted based on pregrazing BW; FDL = sorted based on BW entering the feedlot; IND = sorted by BW and fat thickness at the end of the feeding period.

${ }^{\mathrm{b}}$ Health costs split equally in the 3 periods for winter, summer, and finishing breakeven and profit or loss determinations.

'Winter breakeven price, $\$ / 45 \mathrm{~kg}$.

d\$/head.

ef Means within row with unlike superscripts differ $(P<0.10)$.

${ }^{9}$ Summer breakeven price, $\$ / 45 \mathrm{~kg}$.

hSlaughter breakeven price, $\$ / 45 \mathrm{~kg}$.

i $\$$ steer if sold on live market basis.

'Premium or discount received if marketed in a value-based market using grid in Table 3, $\$ / 45 \mathrm{~kg}$.

$\mathrm{k} \$ /$ steer if sold on value-based market using grid in Table 3.

were sorted into 2 marketing groups when 3 groups may have been more appropriate Variation in HCW was decreased by PST and FDL suggesting sorting improved uniformity of cattle marketed. Identification of the heaviest animals prior to grazing allows for removal of animals early if forage becomes limiting. Cattle removed early from grass may be expected to have greater MARB, less DMI, reduced ADG, and similar feed efficiencies. Interpretation of these data should be limited to yearling systems utilizing ranch-source calves. Additional research comparing sorting strate- gies to unsorted controls in different production systems is needed to determine optimal sorting methods.

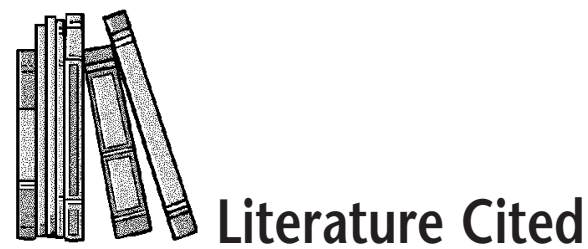

Basarab, J. A., D. Milligan, J. J. McKinnon, and B. E. Thorlakson. 1997. Potential use of video imaging and real-time ultrasound on incoming feeder steers to improve carcass uniformity. Can. J. Anim. Sci. 77:385.

Bernardo, D. J., and F. T. McCollum. 1987. An economic analysis of intensive-early stocking. Oklahoma Agric. Exp. Stn. Rep. P887.

Cooper, R., T. Klopfenstein, and T. Milton. 2000. Sorting or topping-off pens of feedlot cattle. Nebraska Beef Cattle Rep. MP-73:43.

Cooper, R., T. Klopfenstein, T. Milton, and D. Feuz. 1999. Feedlot marketing/sorting systems to reduce carcass discounts. Nebraska Beef Cattle Rep. MP-71A:57.

Feuz, D. M., P. A. Burgener, and T. Holman. 2001. Historical cattle and beef prices, seasonal patterns, and future basis for $\mathrm{Ne}$ braska, 1960-2000. Univ of Nebraska Coop. Ext. Bull. PHREC 01-21, Lincoln.

Feuz, D. 2002. A simulated economic analysis of altering days on feed and marketing cattle on specific value-based pricing grids. Nebraska Beef Cattle Rep. MP-79:39.

Fox, D. G., and T. C. Perry. 1996. Predicting optimum endpoints for finishing cattle. In 
The Composition of Growth in Beef Cattle in Honor of Rodney L. Preston, Ph.D.. pp 38-48. Texas Tech. Univ., Lubbock.

Houghton, P. L., D. D. Simms, and J. J. Higgins. 1990. Comparison on steer feedlot performance and carcass trait uniformity by method of sorting. Kansas State Cattlemen's Day Progress Rep. 592:75.

Johnson, B. 2001. Cornhusker economics. Univ. Nebraska Coop. Ext. Serv., Lincoln.

Jordon, D. J. 2000. Performance and slaughter breakeven analysis of calf and yearling systems and compensatory growth. Ph.D. Dissertation. Univ. of Nebraska, Lincoln.

Klopfenstein, T., R. Cooper, D. J. Jordon, D. Shain, C. Calkins, and C. Rossi. 2000. Effects of backgrounding and growing programs on beef carcass quality and yield. Proc. Am. Soc. Anim. Sci. 1999. Available at http://www.asas.org/jas/symposia/ proceedings/0924.pdf. Accessed February 4, 2002.

MacDonald, J.C. 2002. Sorting strategies in an extensive forage utilization beef production system. M.S. Thesis. Univ. of Nebraska, Lincoln.

Smith, M. T., J. W. Oltjen, H. G. Dolezal, D. R. Gill, and B. D. Behrens. 1989. Evaluation of ultrasound for prediction of carcass fat thickness and ribeye area in feedlot steers. Oklahoma Agric. Exp. Stn. Rep. MP127:291.

Strasia, C. A., S. L. Harp, B. J. Skaggs, R. L. Schemm, D. L. Deen, C. L. Schultz, D. R. Gill, R. B. Hicks, and S. D. Kraich. 1988. The effect of sorting on feedlot animal performance. Olkahoma Agric. Exp. Stn. Rep. MP125:161.

Trenkle, A. 2001. Effects of sorting steer calves on feedlot performance and carcass value. Iowa State Beef Rep. A.S. R1740.
Trenkle, A., and J. C. Iiams. 1997. Potential value of ultrasound to sort feeder cattle into more uniform groups for finishing and marketing. Iowa State Beef Rep. A.S. R1432.

Van Koevering, M. T., D. R. Gill, F. N. Owens, H. G. Dolezal, and C. A. Strasia. 1995. Effect of time on feed on performance of feedlot steers, carcass characteristics, and tenderness and composition of longissimus muscles. J. Anim. Sci. 73:21.

Vieslemeyer, B. A., R. J. Rasby, B. L. Gwartney, C. R. Calkins, R. A. Stock, and J. A. Gosey. 1996. Use of expected progeny differences for marbling in beef: I. Production traits. J. Anim. Sci. 74:1009.

Wellman, A. 1998. Crop and livestock prices for Nebraska. EC883. Univ. of Nebraska Coop. Extension Serv., Lincoln. 